\title{
Monographs on Pediatric Environmental Health: A Cooperative Agreement Award from the Agency of Toxic Substances and Disease Registry of the CDC
}

\author{
Erica L. Liebelt MD, FACMT
}

Editor, Pediatric Environmental Health Monographs

In 2004, the American College of Medical Toxicology received a cooperative agreement award from the Agency for Toxic Substances and Disease Registry of the CDC. The award is entitled a "Program to Build Capacity to Conduct Environmental Medicine and health Education Activities". As part of that agreement, in collaboration with the Association of Occupational and Environmental Clinics and Pediatric Environmental Health Specialty Unit (PEHSU) Program, ACMT prepared two educational monographs to address common yet challenging questions regarding pediatric environmental toxicology. A team of ACMT members who are pediatric medical toxicologists and PEHSU members developed two short monographs in question and answer format.
The monographs are designed to help the staff of PEHSU clinics respond to the many telephone inquiries they receive on topics regarding pediatric environmental toxicology. A survey was taken among PEHSU constituents as to what topics would be most helpful. Phthalates in Food and Medical Devices and Pesticides on Foods were chosen. Drs. Robert Geller and Robert Wright were the primary ACMT authors. The primary peer reviewers were PEHSU members and included Nancy Beaudeat MS CIH, Jay Mayefsky MD MPH, Larry Lowry PhD, and Nathan Graber MD. These monographs are exemplary of a true collaborative educational initiative between two professional organizations that promote children's health in the environment. 